https://doi.org/10.46344/JBINO.2020.v09i05.22

\title{
NON-PLACENTAL INTRAUTERIN OXYGENATION OF FETUS- Review article
}

--Intramuscular and/or intra gastric injection solution of hydrogen peroxide inside the uterus is proposed as a method of non-placental oxygenation of fetal blood.

\section{N.A.Urakova}

'Department of Obstetrics and Gynecology of the Izhevsk State Medical Academy of the Ministry of Health Russian Federation, Izhevsk, Russia - 426034

(Received on Date: $27^{\text {th }}$ July 2020

Date of Acceptance: $11^{\text {th }}$ August 2020

Date of Publish: $4^{\text {th }}$ September 2020)

E-mail: urakovnatal@mail.ru

\section{ABSTRACT}

The review is devoted to the development of drugs and methods of their introduction into the fetal body to protect its brain from hypoxic damage in intrauterine hypoxia. The results achieved on this path in Russia are shown. The chronological sequence shows inventions and innovative developments aimed at intrauterine control of asphyxia of newborns using ultrasound assessment of fetal resistance to hypoxia, intrauterine ventilation of the fetus with respiratory gas and intragastric or intramuscular injections of a solution of hydrogen peroxide. Based on the analogy of the dynamics of motor activity of aquarium fish and fetuses inside the uterus in acute hypoxia, it is proposed to consider the "breathing" movements of the chest and arms of the fetus that suddenly appear after a stationary period as a distress signal that the fetus sends when its reserves of adaptation to hypoxia are exhausted. To save the cerebral cortex and the life of the fetus when there is a lack of oxygen supply to it from the mother, it was initially proposed to ventilate the lungs of the fetus with respiratory gas using a special intrauterine scuba. Then, to preserve life in conditions of lack of oxygen, it was proposed to use not a gas, but a solution of hydrogen peroxide, which can be injected into skeletal muscles, into the brain and/or into the stomach cavity. It is shown that a solution of hydrogen peroxide can be introduced into the stomach using an intragastric probe. The main inventions and scientific articles devoted to these developments are indicated.

Key words: fetal hypoxia, resistance, oxygen, hydrogen peroxide, non-placental oxygenation. 


\section{Introduction}

Pregnant women, as well as obstetricians and gynecologists still do not have effective and safe means, devices and ways to eliminate sudden intrauterine hypoxia of the fetus ${ }^{1,2}$. Therefore, the lack of oxygen remains the most terrible obstacle for the fetus during its intrauterine development and birth. 3,4 The fact is that the lack of oxygen in the mother's womb is still the main cause of fetal death during pregnancy and childbirth. 5 This is surprising, since air with oxygen is in excess near the suffocating fetus, namely, around the body of its mother. Physically, the air with life-giving oxygen is only a few centimeters away from the fetus. But they are separated from each other by the anterior abdominal wall and the wall of the uterus of a pregnant woman. At the same time, the fetal respiratory system is ready for air ventilation and for absorption of oxygen from the air from the middle of pregnancy. 6 This means that intrauterine and/or extrauterine ventilation of the fetal lungs with respiratory gas is a very real task. ${ }^{7}$ But intrauterine ventilation of the fetus lungs with gas is a difficult task for clinical practice and a dangerous procedure for the fetus, since it requires excessive gas pressure, as in adults when diving at great depth.

On the other hand, we can try to save the fetal brain from hypoxic damage and without ventilating the lungs with respiratory gas, in particular, through extracorporeal membrane oxygenation (ECMO). But this technology is also likely to be very complex and very expensive. 8,9 Moreover, intrauterine ECMO can be more complex and expensive than intrauterine ventilation of the fetus with respiratory gas.Another way to preserve the fetal brain when there is a lack of oxygen supply from the mother is extra pulmonary blood oxygenation without ECMO. But this path is little explored.

However, until recently, no one knew how a person can go into outer space and stay alive without air. But this problem was successfully solved. And for the first time, this happened thanks to Russian cosmonauts. In this regard, it is hoped that intrauterine oxygen supply to the fetus will also be solved not without the participation of Russian researchers.

The aim of the study is to demonstrate the results of Russian innovations in the field of non-placental blood oxygenation of the fetus inside the mother's womb.

\section{Methods}

Scientific and patent literature was analyzed using E-Library, EAPATIS, PATENTCSOPE, Google Patent, Google Scholar, Scopus, PubMed, Science Direct and Yandex databases. Keywords of the search strategy were as follows: pregnancy, fetus, fetal hypoxia, intrauterine hypoxia, cerebral cortex, neonatal asphyxia, resistance, adaptation to hypoxia, antihypoxants, oxygen, pulmonary oxygenation, extrapulmonary oxygenation, hydrogen peroxide, sonography, diagnostics, scuba. Keywords were limited to medicines, biomedical devices and technologies for emergency care in critical situations at the end of pregnancy, before or during childbirth caused by sudden intrauterine hypoxia of 
the fetus. The results were analyzed, prioritized, and summarized.

\section{Results}

The first proposal about nonplacental oxygenation of fetal blood was made by Professor A. L. Urakov. In 2012, he was the first to publish an article that gas exchange in the fetal body can be provided by artificial respiration by ventilating the fetal lungs with respiratory gas inside the uterus and suggested using a special breathing mask for the intrauterine fetus (intrauterine scuba) for this purpose. 10 In this article, he wrote that the placenta, due to its special anatomical structure and physiological functioning, provides a supply of maternal blood to the blood coming to it from the fetus. In other words, the placenta is not so much "fetal respiration" as "maternal blood supply of fetal blood" (the author's term).

The possibility of intrauterine respiration in a fetus in the third trimester of pregnancy has been proven in
Australia in experiments on intrauterine lambs and pregnant sheep. In these experiments, it was shown for the first time that transabdominal insertion of an intubation tube into the trachea of a premature intrauterine lamb provides ventilation of its lungs and natural respiration of the lamb, despite its presence in the mother's womb.11 Regardless of these studies, a new medical device designed for intrauterine ventilation of the fetus was developed in Russia. This device was called an intrauterine scuba device by $\mathrm{N}$. A. Urakova. ${ }^{12}$ Later in this article, Professor A. L. Urakov wrote that intrauterine scuba Urakova N.A. includes a ventilator and breathing circuit with a special folding (inflatable) respiratory mask is inserted into the uterus through the natural opening in the cervix, to be worn on the head of the fetus inside the uterus and ensures ventilation of the lungs of the fetus breathing gas to eliminate his asphyxia (Figure 1).

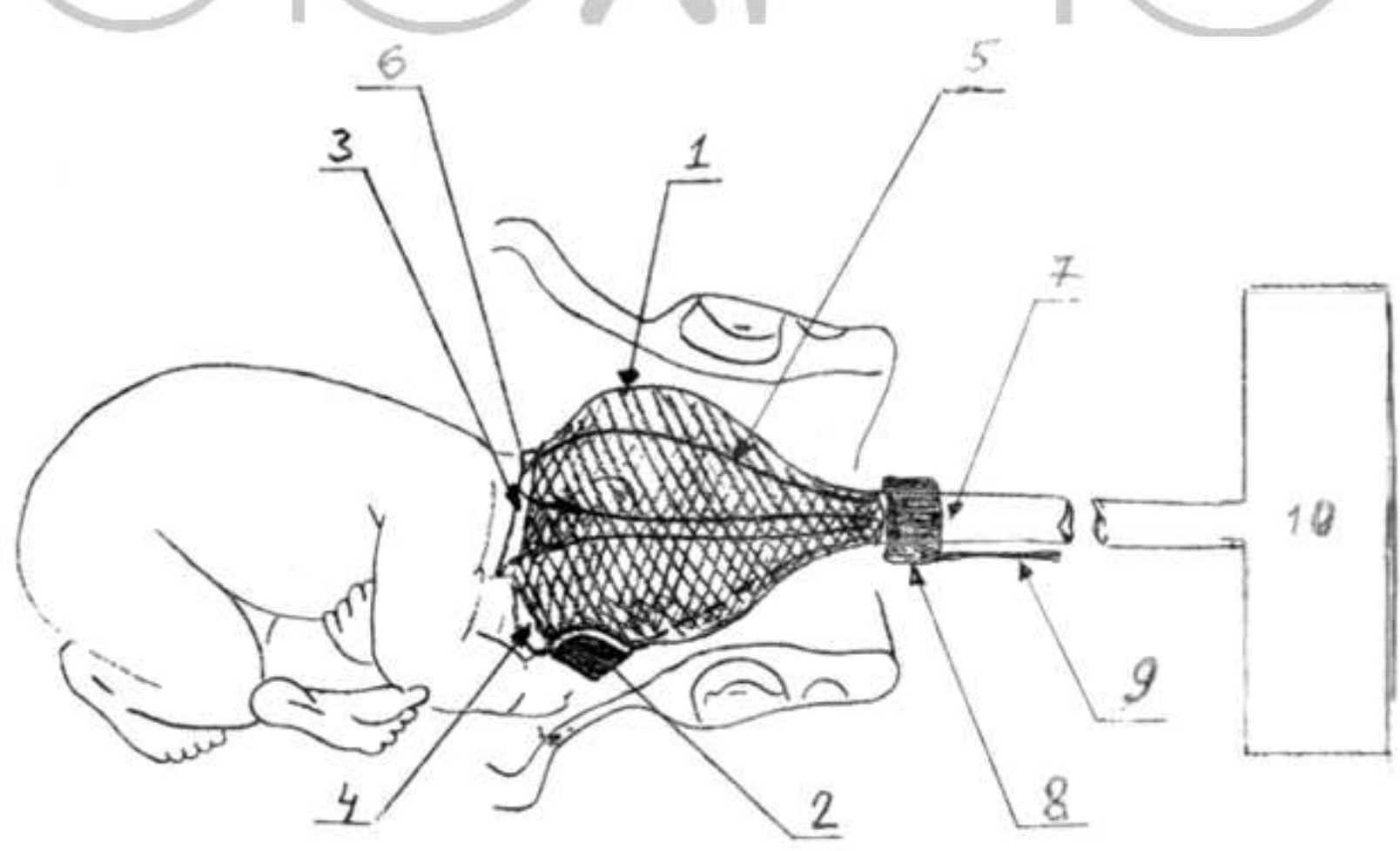


Figure 1. Diagram of the device for artificial ventilation of the intrauterine fetus. Designations: 1 - mesh from the air belt in the form of a stocking, 2 - a respiratory mask, 3 - collar 4 - segment extension collar, 5 - pusher of gelatin spokes, bent in half with the formation of semicircle 6, 7 - multi-channel tube, 8 inflatable cuff with a flexible tube 9, 10 ventilator, equipped with a sterilizer, heater and humidifier of the breathing gas, and suction.

In addition, the article describes the technology of using a device for artificial respiration of an intrauterine fetus, including putting a breathing mask on the head of the fetus inside the uterus and artificial ventilation of the lungs of the intrauterine fetus with respiratory gas.

Prior to this, the idea of intrauterine ventilation of the fetus was announced in the form of abstract at a conference held in mid-June 2011 in Norway. ${ }^{13}$

At the same time a method for sonographic assessment of fetal resistance to intrauterine hypoxia was developed for the first time in Russia. ${ }^{14-16}$ This method was developed by analyzing the results obtained in studies of the dynamics of motor activity during acute hypoxia in aquarium fish and fetuses inside uterus in pregnant women. ${ }^{17}$ At the same time, it was found that when the reserves of adaptation to hypoxia are exhausted, aquarium fish and human fetuses send a distress signal in the form of a sudden start of "breathing" movements of the chest ribs, flapping of the arms (fins) and convulsive contractionsrelaxation of skeletal muscles. ${ }^{18-22}$

The discovery of this pattern allowed us to propose a new functional test for obstetricians with apnea in a pregnant woman to assess the resistance of her fetus to hypoxia, as well as a new method for screening antihypoxants, based on the dynamics of motor activity of aquarium fish in acute hypoxia in the experiment.

In turn, the results of experiments with aquarium fish allowed us to find out that the solution of hydrogen peroxide is a leader among antihypoxants. Professor A. L. Urakov and his students first proposed using a solution of hydrogen peroxide to keep fish alive during transportation and storage, as well as to resuscitate patients with hypoxia instead of oxygen gas. ${ }^{23-27}$ The results of these studies have allowed the development of several reviving methods and drugs, which are based on the ability of hydrogen peroxide to decompose into gas oxygen and water under the action of the enzyme catalase. $28-32$

In particular, Professor A. L. Urakov was the first in the world to suggest injecting a solution of hydrogen peroxide into the stomach cavity, into skeletal muscles, and even into the cerebral cortex in acute hypoxia and/or ischemia. $33-35$

\section{Conclusion}

Thus, Russian scientists were the first to develop spacesuits for astronauts and aqualungs for fetuses in order to ventilate their lungs with breathing gas both in the airless space in space and in the amniotic fluid inside the uterus of pregnant women. In recent years, air and oxygen gas have been replaced with aqueous solutions of hydrogen peroxide. Today, a new innovation is proposed for extra placental intrauterine blood oxygenation of the fetus, namely, airless 
extrapulmonary oxygenation by injection of a solution of hydrogen peroxide. There is every reason to believe that very soon this fantasy will come true and intrauterine hypoxia will be finally defeated.

\section{Conflict of interest:}

None declared.

\section{References}

1. Hutter D, Kingdom J, Jaeggi

E. Causes and mechanisms of intrauterine hypoxia and its impact on the fetal cardiovascular system: a review. Int J Pediatr.

2010;2010:401323.

doi:10.1155/2010/401323.

2. Urakov A, Urakova N. Fetal hypoxia: Temperature value for oxygen exchange, resistance to hypoxic damage, and diagnostics using a thermal imager. Indian J Obstet Gynecol Res 2020;7(2): $\quad 232 \quad-238$. https://creativecommons.org/licenses/by -nc/4.0/.

\section{Nalivaeva NN, Turner AJ,} Zhuravin IA. Role of Prenatal Hypoxia in Brain Development, Cognitive Functions, and Neurodegeneration. Front Neurosci. 2018;12:825. Published 2018 Nov 19. doi:10.3389/fnins.2018.00825.

4. Urakova NA, Urakov AL, Nikolenko VN, Lovtsova LV. Application of Infrared Monitoring for Personalization of Obstetric Aid. Modern Technologies in Medicine. 2019. V.11. № 4. P. 111 - 119. doi: 10.17691/stm2019.11.4.13.

\section{Urakova NA, Urakov AL.} Thermal Imaging for Increasing the Diagnostic Accuracy in Fetal Hypoxia: Concept and Practice Suggestions. Application of Infrared to Biomedical Sciences, Series in BioEngineering, Editors:
E.Y.K. Ng and M. Etehadtavakol. Springer Nature Singapore Pte Ltd. $2017 . \quad$ P. 277 289. DOI 10.1007/978-981-10-3147-2_16.

6. How children's lungs grow. https://www.blf.org.uk/support-foryou/how-childrens-lungs-grow.

7. Urakov A. Intrauterine lungs ventilation of human fetus as saving his life during hypoxia myfh or reality? J. Perinat. Med. 41 (2013). P. 476.

8. Makdisi G, Wang I-wen. Extra corporeal membrane oxygenation (ECMO) review of a lifesaving technology. J Thorac Dis. 2015; 7(7): E166E176. doi: 10.3978/j.issn.20721439.2015.07.17.

9. Urakov AL. COVID-19: Original simple and cheap extrapulmonary oxygenation as an alternative to ECMO. J.Bio.Innov.2020;9(4):648-654. https://doi.org/10.46344/JBINO.2020.v09i0 4.27.

10. Urakov AL. Ventilation mask fetus (intrauterine scuba) and way to ensure gas exchange in the fetus by means of artificial respiration (his lung ventilation breathing gas) inside the uterus. Advances in Current Natural Sciences. 2012; 10:58-62. https://www.naturalsciences.ru/pdf/2012/10/11.pdf.
11.
Allison
B, Crossley
K, Flecknoe S, Morley C, Polglase G, Hooper S. Pulmonary hemodynamic responses to in utero ventilation in very immature fetal sheep. Respir. Res. 2010; 11:111. Doi: https://doi.org/10.1186/1465-9921-11-111.

12. Urakov $\mathbf{A L}$, Urakova NA, Kasatkin AA, e.al. Intrauterine scuba $\mathrm{N}$. A. Urakova and method of ventilating fetal lungs with respiratory gases. The application for the invention of Russia No. 
2010134466. Bulletin of Inventions and Industrial Models. 2012; 6:38-39.

\section{Urakov $A L$, Urakova NA,} Kasatkin AA, Gausnekht MY. Trouble intrauterine hypoxia by his lung ventilation respiratory gas through intrauterine aqualung. Abstracts 31 st Congress Scandinavian Society of Anaesthesiology and Intensive Care Medicine «Patient Safety through Audit and Simulation» (15 17 June 2011, Bergen, Norway). Bergen, 2011:9.

14. Urakov AL, Urakova NA, Sokolova NV e.all. Method for assessment of fetus resistance to hypoxia by M.Y.Gausnekht. RU Patent 2432118. (27.10.2011).

15. Urakov AL, Urakova NA, Urakova TV e.all. Method for labor by N.V. Sokolova. RU patent 2441592. (10.02.2012).

16. Urakova NA, Urakov AL. The stability of the fetus to hypoxia and to birth. Bulletin of the Russian Military Medical Academy. 2012; 40(4): 221-223. https://www.vmeda.org/wp-

content/uploads/2016/pdf/221-223.pdf.

17. Urakov AL, Urakova NA, Gauskneht MY, Chernova LV. Diagnostic symptoms of hypoxia in fetuses in the womb and in fish in the water. International Research Journal. 2013; 18(11-3): $\quad 53 \quad$ - 54. https://www.elibrary.ru/item.asp? id=21 10 5024.

\section{Radzinsky VE, Urakov AL,} Urakova NA, Gauskneht MY. Assessment of the sustainability of the fetus to intrauterine hypoxia during the period of breath-holding a pregnant woman. Reproductive Health. Eastern Europe. 2012; 1: 119-127.
19. Urakova NA. Comprehensive ultrasound and infrared diagnostics of fetal hypoxia during pregnancy and childbirth. Problems of Expertise in Medicine. 2013; 3: 26-29.

20. Urakov AL, Urakova NA, Chernova LV. Analogies of behavior of fish in water and fetuses in the womb of pregnant women with acute hypoxia. International Journal of Experimental Education. 2014; 1-2: 83-86; doi: http://www.expeducation.ru/ru/article/vi ew?id=4561.

21. Urakova N, Urakov A, Gausknekht $\mathbf{M}$. Russian innovative ultrasonic method of assessing the sustainability of the fetus to hypoxia as the opportunity of forecasting of asphyxia, perinatal outcomes and the choice of the method and term of delivery. J. Perinat. Med. 2013;41: 183.

22. Urakov AL, Urakova NA. Ultrasonic monitoring of the motor activity of the fetus during the breath of a pregnant woman - a new functional test for the stability of the fetus to hypoxia.18TH World Congress on Controversies in Obstetrics, Gynecology \& Infertility (COGI) (October 24-27, 2013, Vienna, Austria) Editor Z. Ben-Rafael. Milano (Italy): Monduzzi editoriale proceedings. 2014; 165-170.

23. Urakov $A L$, Urakova NA, Chernova LV. The influence of temperature, atmospheric pressure, antihypoxant and chemical "battery oxygen" on the sustainability of fish in the water without air. International Journal of Applied and Fundamental Research. 2014; 8: 1-5. https://www.elibrary.ru/item.asp?id=21 65 3833. 
24. Urakov AL, Urakova NA, Chernova LV. Hydrogen peroxide solution may become a rival gas oxygen during resuscitation. Advances in Current Natural Science. 2014; 12: 198-203. URL: www.rae.ru/use $/$ ? section $=$ content $\& O p=s$ how article\&article id $=10003408$.

(available : 01.01.2015).

25. Urakov AL, Urakova NA, Chernova LV. A solution of hydrogen peroxide can become a competitor to oxygen gas during resuscitation. Advances in Modern Natural Science. 2014; 12(3): 198-203. doi: http://www.naturalsciences.ru/ru/article/view?id=34569.

26. Urakov AL, Urakova NA, Agarval RK, e.all. Method of maintenance of live fish during transportation and storage. RU Patent 2563151. 20.09.2015.

27. Urakov AL. Hydrogen peroxide can replace gaseous oxygen to keep fish in hypoxia. International Research Journal. 2017; 5-2(59):106-108. doi:

https://doi.org/10.23670/IRJ.2017.59.109.

28. Urakov AL, Urakova NA, Nikityuk DB. Agent for increasing resistance to hypoxia. RU Patent 2604129. 10.12.2016.

29. Urakov AL. Lympho-substitute for local maintaining viability of organs and tissues in hypoxia and ischemia. RU Patent 2586292. 10.06.2016.

30. Gots IR, Urakov AL. Energy drink. RU Patent 2639493. 21.12.2017.
31. Urakov AL. Means for physical endurance increase. RU Patent 2634271. 24.10.2017.

32. Urakov AL, Urakova NA. COVID-19: Cause of death and medications. IP International Journal of Comprehensive and Advanced Pharmacology. 2020; 5(2): 45-48. doi: https://creativecommons.org/licenses/by - nc/4.0/.

33. Urakov AL, Urakova NA, Chernova LV. Influence of temperature, atmospheric pressure, antihypoxants and chemical "oxygen accumulator" on the viability of fish in water without air access. International Journal of Applied and Fundamental Research. 2014;8(2):48 - 52. https://applied-

research.ru/ru/article/view? $\mathrm{id}=5580$.

34. Urakov AL. The introduction of a hyperoxygenated solution of hydrogen peroxide into the stomach increases the body's resistance to hypoxia. Advances in Modern Natural Science. 2015;1:946-950.

http://www.natural-

sciences.ru/ru/article/view? id=34980.

35. Urakov AL. Substitute of lymph. A new drug for local prevention of ischemic and hypoxic damage to organs and tissues. International Journal of Applied and Fundamental Research. 2016; 6(1): 78-79. https://appliedresearch.ru/ru/article/view?id=9554. 